\title{
Essai d'infection de chèvres tchadiennes par le virus de la rhinotrachéite infectieuse bovine. Enquête sérologique dans l'Ouest Tchadien
}

\author{
par Y. MAURICE et A. PROVOST (*) \\ avec la collaboration technique de Z. N'GALDAM et R. GONDO
}

RESUME

L'impossibilité de reproduire cliniquement la rhinotrachéite infectieuse bovine chez la chèvre ainsi que les constatations nécropsiques et sérologiques relevées après l'infection expérimentale, le faible pourcentage de sérums positifs et le très faible taux des anticorps décelés dans les sérums de chèvres vivant dans une zone où la rhinotrachéite infectieuse bovine est très répandue ne permettent pas de penser que cet animal soit un relai actif dans l'épizootiologie de la maladie.

Le virus de la rhinotrachéite bovine infectieuse n'intervient vraisemblablement pas dans la pathologie respiratoire de l'espèce caprine.

La réceptivité de la chèvre à la rhinotrachéite bovine infectieuse (R.B.I.) a été peu étudiée. MAC KERCHER et ses collaborateurs (2) ont signalé la réceptivité des caprins à cette infection qui se manifesterait par de la température et des signes discrets de maladie. Plus récemment, VAN HOUWELING (4) avait envisagé, par souci d'économie, la possibilité d'utiliser la chèvre pour tester les vaccins contre la rhinotrachéite infectieuse bovine. Cette possibilité fut écartée, car après avoir exposé des caprins à une souche pathogène du virus R.B.I., il put constater que, contrairement aux résultats obtenus par les premiers auteurs, les chèvres étaient insensibles à ce virus inoculé par voie intracérébrale ou par voie nasale: aucune pointe thermique, aucun signe clinique ne furent notés et aucun anticorps spécifique détecté chez ces animaux après contact avec le virus. Cependant le virus R.B.I. fut réisolé des fosses nasales de

( $^{*}$ I.E.M.V.T., Laboratoire de Recherches vétérinaires de Farcha, Fort-Lamy, Tchad. certaines chèvres 5 jours après le contact virulent.

La rhinotrachéite infectieuse bovine existe en Afrique et au Tchad en particulier où le virus a été isolé et identifié par PROVOST et collab. (3). L'infection est même assez répandue si l'on en juge d'après les sondages sérologiques. Dans le cadre de l'étude des maladies respiratoires de la chèvre au Tchad, on a étudié la réceptivité de cette espèce à cette maladie et lincidence de cette dernière dans certains effectifs caprins du Tchad vivant dans les conditions naturelles.

\section{MATERIEL ET METHODES}

\section{Méthode d'infection}

Onze chèvres de la région de Fort-Lamy, ne possédant pas d'anticorps sériques neutralisants anti virus R.B.I, sont soumises à un aérosol infectieux qui reproduit une modalité vraisemblablement fréquente de la transmission natu- 
relle du contage, tout au moins chez les bovins. Pour ce faire, on utilise un appareil générateur d'aérosols médicamenteux Jouan délivrant des particules de l'ordre du micron et débitant $12 \mathrm{ml}$ de liquide à l'heure. Les animaux sont exposés pendant $5 \mathrm{mn}$. ce qui correspond donc à $1 \mathrm{ml}$, c'est-à-dire $10^{5,16} \mathrm{DCP}_{50}$, de virus de la rhinotrachéite infectieuse bovine avec les liquides pathogènes utilisés. Pour l'insufflation, un manchon en matière plastique souple relie le générateur au mufle de la chèvre. De plus, tous ces animaux sauf 2 (n ${ }^{o s} 5698$ et 5196) reçoivent également par voie intraveineuse, $7 \mathrm{ml}$ de liquide virulent de cultures cellulaires ayant servi à l'aérosol.

\section{Souche de virus R.B.I.}

En l'absence de souche de virus R.B.I. isolée de l'espèce caprine, c'est la souche bovine Ithaca, à tropisme respiratoire qui a été utiliséc dans cette expérience. Cette souche, d'origine américaine, n'a subi que 3 passages en cellules d'embryon de veau depuis son isolement et n'a été repassée, ni sur bovin ou toute autre espèce animale, ni sur cellules depuis son arrivée à Farcha.

Le matériel virulent est constitué, tant pour l'aérosol que pour les inoculations intraveineuses, par le broyat des cellules et le liquide de culture des cellules rénales d'embryon de veau infectées avec la souche originale, cellules et liquide de ce $4^{\mathrm{e}}$ passage étant récoltés au maximum d'effet cytopathique du virus. Le titrage en culture cellulaire de rein d'embryon de veau de ce liquide virulent, lui assigne le titre de $10^{5,16} \mathrm{DCP}_{50}$ par $\mathrm{ml}$; son pouvoir pathogène est vérifié sur un bouvillon sensible maintenu en étable d'isolement.

\section{Animaux d'expérience}

On utilise 11 chèvres de la région de FortLamy sans anticorps neutralisant anti-virus R.B.I. Elles sont logées dans un box commun. Une prise de sang est effectuée avant l'aérosol et l'inoculation ainsi que le $23^{\mathrm{e}}$ jour suivant le contact virulent. Un jour avant l'infection expérimentale puis, tous les jours ensuite, on prend les températures rectales. Du mucus nasal est prélevé chez tous les animaux par écouvillonage les $5^{\mathrm{e}}$ et $6^{\mathrm{e}}$ jours. Les chèvres sont abattues le $23^{\mathrm{e}}$ jour et les autopsies aussitôt pratiquées. Le foie, la rate, le cceur, les reins, les poumons et les ganglions lymphatiques (pulmonaires et mésentériques) sont prélevés pour étude anatomo-pathologique.

\section{Isolement du virus}

Les écouvillons de sécrétions nasales prélevés les $5^{\mathrm{e}}$ et $6^{\mathrm{e}}$ jours après l'aérosol et l'inoculation sont placés aussitôt dans une solution tamponnée phosphatée avec antibiotiques et placés ensuite à $-15^{\circ} \mathrm{C}$ jusqu'au lendemain. L'ensemble est alors décongelé et le liquide est inoculé à des cellules de rein d'embryon de veau de $2^{\mathrm{e}}$ explantation. Après l'inoculation et une heure d'adsorption à $37^{\circ} \mathrm{C}$, on remet en culture dans un milieu au sérum de poulain. Des broyats des poumons des chèvres prélevés lors de l'abattage sont également inoculés individuellement à des cellules de même nature entretenues 'dans le même milieu.

\section{Identification du virus}

Elle est faite par séroneutralisation en culture cellulaire de rein d'embryon de veau de $2^{\mathrm{e}} \mathrm{ex}-$ plantation, en utilisant la technique dite à sérum constant-virus variable. Les dilutions en liquide de Hanks du virus de référence (souche Ithaca de cette expérience) et du virus isolé à partir de l'écouvillon nasal et à identifier, sont mises chacune en incubation pendant une heure à $37^{\circ} \mathrm{C}$, avec une quantité égale de sérum bovin anti R.B.I. d'une part et de sérum bovin sans anticorps anti R.B.I. d'autre part. Puis des quantités de $0,1 \mathrm{ml}$ de ces mélanges aux différentes dilutions de virus sont portées dans des tubes de cultures cellulaires de rein d'embryon de veau de $2^{\mathrm{e}}$ explantation, et rincés trois fois au Hanks. Après une heure d'adsorption à $37^{\circ} \mathrm{C}$, on remet en culture dans un milieu au sérum de poulain. L'antisérum a été obtenu en infectant par voie conjonctivale une génisse maintenue en étable d'isolement avec la souche Ithaca : elle est saignée 50 jours après l'infection et l'on s'assure que son sérum qui ne neutralisait pas ce virus R.B.I. avant l'infection le neutralise maintenant à un taux élevé (3).

\section{Séroneutralisation, enquête sérologique}

La technique de séroneutralisation suivie est inspirée de celle de GREIG (1) utilisée en 1964 par PROVOST et collab. (3) à Farcha. La banque de virus pour séroneutralisation correspond au même matériel que celui qui a servi à 
l'inoculation et à l'aérosol. Au départ et au moment de l'utilisation de cette banque pour l'enquête sérologique deux mois plus tard, le titre était de $10^{5,16} \quad \mathrm{DCP}_{50} / \mathrm{ml}$. Les sérums sont d'abord examinés purs. Ils correspondent à 561 sérums de chèvres de la région de FortLamy prélevés à l'abattoir de cette ville. Les sérums sont conservés à $-20^{\circ} \mathrm{C}$ avant l'utilisation.

\section{Clinique}

\section{RESULTATS}

Aucune chèvre n'a extériorisé de signe clinique de maladie pendant les 23 jours suivant l'aérosol et l'inoculation. Les animaux n'ont manifesté aucune hyperthermie et les courbes de température sont sans signification. La chèvre $\mathrm{n}^{\circ} 5177$, en mauvais état, est morte 24 heures après l'aérosol et l'inoculation.

\section{Isolement et identification de virus}

Un virus cytopathogène en 48 heures pour les cellules rénales d'embryon de veau et déterminant des lésions caractéristiques du groupe herpétique, a été isolé dans les écouvillonages nasaux du $5^{\mathrm{e}}$ jour chez deux animaux. Dans les deux cas, ces virus se sont révélés par séroneutralisation être des virus R.B.I., les deux souches étant neutralisées par l'immunsérum alors qu'elles ne l'étaient pas dans le sérum négatif. Les essais d'isolement à partir des poumons se sont révélés négatifs.

\section{Examens anatomo-pathologiques}

A l'abattage, aucune lésion n'a été constatée et les examens des coupes anatomo-pathologiques effectuées au niveau des différents organes des 11 chèvres n'ont rien montré de particulier, exception faite d'un animal qui possédait une lésion d'emphysème pulmonaire au niveau du bord supérieur du lobe apical droit du poumon $\left(\mathrm{n}^{\circ}\right.$ 2076).

\section{Résultats sérologiques du $23^{\mathrm{e}}$ jour de l'infection}

Les résultats obtenus par séroneutralisation en culture cellulaire sont rapportés dans le tableau $\mathrm{n}^{\circ} 1$.

T1tre en anticorps neutralisants des sërums prélevës avant et après 1 'infection expérimentale.

\begin{tabular}{|c|c|c|}
\hline $\begin{array}{l}\mathrm{N}^{0} \text { des } \\
\text { animaux }\end{array}$ & $\begin{array}{l}\text { Avant l'infection } \\
\text { Sérum pur } \\
\text { Sérum dilué au } 1 / 2 \\
\text { Sérum dilué au } 1 / 4\end{array}$ & Après l'infection \\
\hline $5177 \cdots$ & - & \\
\hline $5700^{\circ}$ & - & - \\
\hline $5160^{\circ}$ & - & $1 / 1$ \\
\hline $2443^{\circ}$ & - & $1 / 2$ \\
\hline $5196^{\circ}$ & - & - \\
\hline $5181^{\circ}$ & - & - \\
\hline $2411^{\circ}$ & - & $1 / 1$ \\
\hline $5698^{\cdots}$ & - & - \\
\hline $2077^{\circ}$ & - & $1 / 1$ \\
\hline $2076^{\circ}$ & - & $1 / 2$ \\
\hline $1096^{\circ}$ & - & - \\
\hline
\end{tabular}

- aérosol et inoculation intraveineuse;

.. aérosol seul;

... morte dès le début de 1 'expérience. 


\section{Enquête sérologique}

Les résultats obtenus par séroneutralisation en culture cellulaire sont rapportés cI-dessous :

\section{Résultats généraux de l'enquête sérologique}

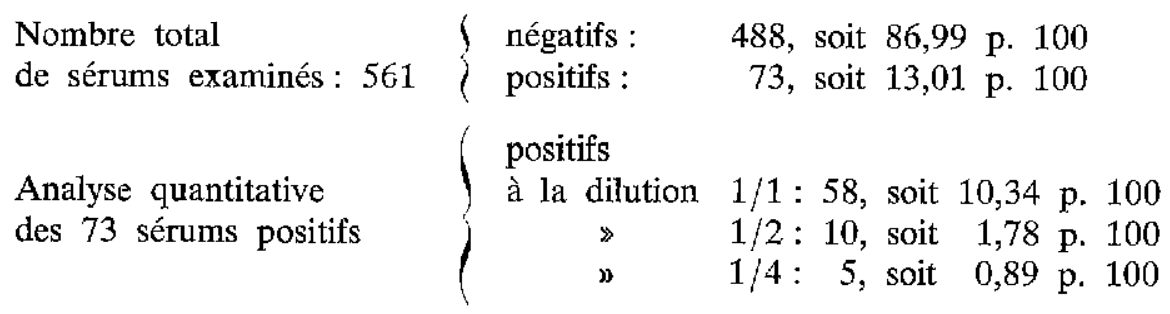

\section{DISCUSSION}

La chèvre du Tchad est insensible cliniquement au virus de la rhinotrachéite bovine infectieuse dans les conditions expérimentales. Celui-ci ne provoque pas chez elle de symptômes ni de lésions caractéristiques comme c'est le cas dans la maladie bovine. Il n'a pas été possible, en particulier, de déceler des lésions au niveau du cortex cérébral (absence de foyers d'inflammations, absence d'inclusions nucléaires du type A de Cowdry) ni du parenchyme pulmonaire (absence de foyers inflammatoires, absence de cellules géantes). Il est bon de préciser que la souche utilisée est une souche à tropisme nettement plus respiratoire que génital. La seule lésion pulmonaire, vraisemblablement ancienne, observée à l'issue de cette expérience est difficilement attribuable à une atteinte du poumon par le virus R.B.I.

L'enquête sérologique montre que seulement 13 pour 100 des sérums étudiés possèdent des anticorps anti R.B.I. à des taux peu élevés (10,34 p. 100 des sérums positifs purs, 1,78 p. 100 positifs à la dilution du $1 / 2,0,89$ p. 100 positifs à la dilution du $1 / 4$, aucun à une dilution supérieure). S'il est bien connu que le virus R.B.I. suscite chez les bovins la formation d'anticorps neutralisants à un taux relativement faible, il n'en reste pas moins vrai que les taux constatés chez les chèvres au cours de cette enquête sont particulièrement bas. Il faut également remarquer que même après l'infection expérimentale chez la chèvre, le titre des anticorps élaborés est très faible à une période où précisément leur taux est considéré comme devant être maximal (23e jour). On conçoit que, dans ces conditions, certains auteurs n'aient pu mettre en évidence des anticorps anti R.B.I. dans cette espèce.

Tout ceci semble montrer que, tant dans les conditions naturelles que dans les conditions expérimentales, la chèvre du Tchad est peu sensible au virus de la rhinotrachéite bovine infectieuse. Il est possible, mais non démontré dans la présente observation qu'il puisse survivre - voire se multiplier - pendant un certain temps chez certains animaux. Cette présence fugace suffirait à susciter une légère réponse sérologique chez quelques sujets. L'absence de lésions spécifiques au niveau des poumons, l'échec des tentatives d'isolement du virus à partir de ces organes prélevés chez des animaux dont 5 d'entre eux, au moins, ne possédaient pas d'anticorps neutralisants dans leurs sérums, autorisent à penser que ce virus n'intervient sans doute pas dans la pathologie respiratoire des chèvres dans les conditions naturelles d'élevage caprin au Tchad. D'ailleurs, à notre connaissance, cet animal n'a jamais été accusé d'être à l'origine d'un foyer de rhinotrachéite infectieuse, ni même de souffrir de la maladie. 